\title{
Resource Description and Access (RDA): prós e contras
}

\author{
Eliane Serrão Alves Mey \\ mey.eliane62@gmail.com \\ Universidade Federal do Estado do Rio de Janeiro \\ Isabel Arino Grau \\ isabel.grau@unirio.br \\ Universidade Federal do Estado do Rio de Janeiro \\ Fernanda Salgado Biar \\ nanda.biar@gmail.com \\ Universidade Federal do Estado do Rio de Janeiro
}

Resumo: Analisa os prós e contras do novo código americano Resource Description and Access (RDA), sob o ponto de vista de um grupo brasileiro de estudos sobre catalogação. O RDA se propõe a tornar-se o código internacional de catalogação. Indubitavelmente, trouxe algumas inovações e vários aspectos positivos, como a introdução de materiais digitais e alguns elementos da família dos Functional Requirements for Bibliographic Records (FRBR). Ao mesmo tempo, o RDA pode ser analisado sob outros aspectos, como o problema das restrições na tradução e seus custos de licenciamento e direitos autorais. Apresentam-se alguns pontos de vista europeus, assim como uma possível solução no caso brasileiro.

Palavras-chave: catalogação; código de catalogação; RDA.

Abstract: It intends to analyze the Resource Description and Access (RDA) code's pros and cons, under one point of view of some Brazilian catalogers. The RDA proposes itself to be an international cataloging code. Undoubtedly, it brings innovations and various positive points, as the introduction of digital materials and some elements from the Functional Requirements for Bibliographic Description (FRBR) family. At the same time, RDA can be analyzed under other aspects, e.g., the problem of a strict translation and the prices for licencing or copyright. Is presents some European point of views about RDA, as well as one possible way to the Brazilian questions.

Keywords: cataloging; cataloging code; RDA.

O presente texto foi parcialmente apresentado em Roma, em Conferência realizada na Biblioteca Vaticana (fevereiro de 2014), em que um dos temas tratava exatamente dos prós e contras do RDA. O trabalho, um dos dez selecionados para publicação em periódico da área entre os mais de cinquenta trabalhos levados à Conferência, foi reduzido devido às limitações estipuladas pelo periódico. Aqui, é apresentado de forma mais completa, e após um contato com outros pontos de vista e outros códigos de catalogação europeus. Por vezes, aparenta uma repetição de fatos por demais conhecidos dos catalogadores, mas pretende-se que vá um pouco além do universo catalográfico. 
Nos anos 80 e 90 do século XX, surgiram a premência de cortar custos na catalogação, a explosão das tecnologias eletrônicas de comunicação (como a internet, levando aos OPACS), a disseminação de novos tipos de itens (como os digitais e os disponíveis on-line), e o desejo de melhor atender às demandas dos usuários, segundo Mey (2009, p.86). A necessidade de realinhar as práticas biblioteconômicas com esses fatores levou às revisões das estruturas dos registros bibliográficos e de conceitos, práticas, códigos e formatos, além de apontar a relevância de fortalecer a catalogação cooperativa e de promover a internacionalização dos padrões de representação. Ao mesmo tempo, estudos como o trabalho de Barbara Tillett sobre relações bibliográficas (1988), que analisou tais relações em catálogos e códigos de catalogação, levaram a uma reavaliação das estruturas conceituais que serviriam de apoio à evolução dos sistemas de catalogação. Artigos como o de Michael Heaney (1995) e Rebecca Green (1996) levantaram questões como o caráter volátil das publicações eletrônicas, a catalogação orientada a objetos e as bases de dados relacionais para a recuperação bibliográfica (apud Mey, 2009, p.88). Já a International Conference on the Principles and Future Development of AACR [Conferência Internacional sobre os Princípios e o Desenvolvimento Futuro do AACR] (Toronto, 1997) evidenciou a vontade de "documentar os princípios básicos subjacentes às regras e análises sobre conteúdo versus continente" (JOINT STEERING COMMITTEE FOR REVISION OF AACR, 2005, p.6) e a necessidade de mudanças no AACR. Segundo Rodríguez García (2010, p.56), as regras de catalogação do modelo americano AACR precisavam de mudanças drásticas, pois não conseguiam representar os novos recursos de informação. Conforme apontou a Conferência de Toronto em 1997, "as regras se ajustavam lentamente aos novos tipos de recursos e não tinham coerência lógica" (ibidem).

Nos anos 90, a IFLA organizou um grupo de estudos sobre os Functional Requirements for Bibliographic Records (Requisitos Funcionais para os Registros Bibliográficos - FRBR), desenvolvendo um modelo conceitual de entidade-relacionamento (IFLA, 2009). Este é "uma visão geral do universo bibliográfico e pretende-se independente de qualquer código ou implementação da catalogação" (Tillett, 2003), contribuindo para "esclarecer conceitos e termos usados no passado e ajudando-nos a explorar novos caminhos de modo a cumprir os objetivos do catálogo" (ibidem). Os catálogos devem permitir que o usuário localize o que precisa, por meio das "tarefas do usuário": encontrar, identificar e selecionar um recurso bibliográfico, obter um item e "navegar em um catálogo e além dele" (IFLA, 2009, p.3-4).

A Declaração de Princípios ("Princípios de Paris"), aprovada pela Conferência Internacional sobre Princípios de Catalogação em 1961, tencionava servir como base para um "entendimento uniforme e internacional sobre os princípios de catalogação" (Mey, 2009, p. 90) e influenciou grande parte dos códigos posteriores. Em 2009, a IFLA publicou o documento 
Statement of International Cataloguing Principles (Declaração de princípios internacionais de catalogação). Essa Declaração de 2009 (IFLA, 2009) sustenta-se "sobre as grandes tradições mundiais da catalogação, assim como no modelo conceitual da IFLA, os Functional Requirements for Bibliographic Records (FRBR)" (idem, p.1), inclusive no tocante às tarefas do usuário. Ela atualizou e ampliou os "Princípios de Paris", abordando não apenas obras textuais mas todos os tipos de materiais e todos os aspectos de dados bibliográficos e de autoridade usados em catálogos de bibliotecas (IFLA, 2009; Tillett, 2007). Gostaríamos de destacar a função "navegar em um catálogo e além dele" por meio dos relacionamentos bibliográficos, presente na Declaração de 2009, função que abre amplas perspectivas às funções de um catálogo, não limitadas a encontrar, identificar e selecionar um recurso bibliográfico.

A definição desses novos princípios internacionais de catalogação para substituir os "Princípios de Paris" ocorreu dentro do plano de "promover o desenvolvimento de um código internacional de catalogação para descrição e acesso bibliográficos" (grifo nosso) (IFLA, 2012). A tarefa ficou a cargo de cinco encontros promovidos pela IFLA em vários continentes entre 2003 e 2007, os International Meetings of Experts on an International Cataloguing Code (IME-ICC) [Encontros Internacionais de Especialistas sobre um Código Internacional de Catalogação]. Além de trabalhar na nova Declaração, o objetivo foi "incrementar a capacidade de compartilhar informação catalográfica em todo mundo, ao promover padrões para o conteúdo de registros bibliográficos e de autoridade usados nos catálogos de bibliotecas" (ibidem). Entre outros tópicos, os IME-ICC revisavam a versão da Declaração trabalhada nos encontros anteriores, examinavam códigos de catalogação locais, comparavam-nos entre si e aos "Princípios de Paris", verificavam se regras e práticas de catalogação poderiam ser mais similares, e faziam sugestões ao novo código internacional de catalogação. Os anais dos Encontros e a Declaração de 2009 foram publicados em diversos idiomas ${ }^{1}$.

Os cinco Encontros levantaram muitas expectativas em todo mundo sobre este novo código internacional de catalogação. Entre outros elementos, supunha-se que seria de livre acesso, sem pagamento de direitos autorais, como a International Standard Bibliogaphic Description (ISBD) [Descrição Bibliográfica Internacional Normalizada]; que poderia incorporar diferentes pontos de vista em questões de catalogação; que tratasse das questões levantadas durante os Encontros; que tivesse base na família FRBR e encorajasse seu uso; que não fosse apenas um AACR2 com nova nomenclatura; e que trabalhasse com banco de dados entidaderelacionamento, e não com um formato hierárquico. Para Tillett (2008, p.4-5), um novo e necessário código de catalogação deve ser consistente quanto aos diversos e mais complexos

\footnotetext{
${ }^{1}$ Arrolados em $\langle$ http://www.ifla.org/node/576 $>$.
} 
tipos de conteúdos e materiais, deve mostrar os pontos em comum dos diferentes tipos de recursos, e retornar a uma abordagem mais voltada aos princípios. Desde 1987, Mey (1987, p. 83; 1995, p. 7-8; 2009, p.10-11) identificava como características necessárias à catalogação: integridade, clareza, precisão, lógica e consistência. Ou seja, verdade no que se registra, clareza para nosso usuário, precisão na identificação do elemento, lógica da organização dos catálogos e dos itens, consistência no uso de normas.

O Joint Steering Committee for Development of RDA [Comitê Geral Conjunto para o Desenvolvimento do RDA] (antigo Joint Steering Committee for Revision of AACR) havia decidido que esse código seria uma nova versão do AACR, ou AACR3. No entanto, durante um encontro em 2005, optou-se por outra abordagem, tendo em vista o cenário muito diferente que então se apresentava. De "AACR3: Resource Description and Access", a proposta passou a chamar-se "Resource Description and Access" (RDA)², ou seja, "Recursos: Descrição e Acesso". Entre outras características, deveria alinhar-se com os modelos FRBR e FRAR (Functional Requirements for Authority Records) [Requisitos Funcionais para Registros de Autoridade] (JOINT STEERING COMMITTEE FOR DEVELOPMENT OF RDA, 2009).

Assim, o RDA (JOINT STEERING COMMITTEE FOR DEVELOPMENT OF RDA, 2013), de um momento para o outro, sepulta o código internacional de catalogação e propõe-se como tal, como seu substituto aceitável. Indubitavelmente, apresenta muitos aspectos positivos. Ao mesmo tempo, pode analisar-se o RDA sob outros aspectos, tais como: a) não se mostra tão próximo à família FRBR como se esperava, conservando uma abordagem mais descritiva em vez de maior compromisso com os modelos relacionais; b) não se mostra tão apartado do AACR como se esperava, na medida em que conserva regras e exemplos para catalogar manifestações, em vez de uma abordagem em vários níveis (obra, expressão, manifestação e item, quando necessário); c) por via de conseqüência, não utiliza todas as possibilidades oferecidas pelas novas tecnologias computacionais; d) o aspecto importantíssimo da tradução: em nosso país, por exigência dos detentores dos direitos autorais, restringiu-se a tradução do AACR2 ao texto original, ipsis litteris, sem incluir soluções e exemplos usados em nosso país e em nosso idioma - esperava-se também que o RDA respeitasse tais questões, o que aparentemente não ocorreu; e) por fim, mas não o menos importante, o preço do RDA.

A nosso ver, o aspecto mais crítico do RDA relaciona-se a seu distanciamento da família FRBR. Os FRBR significaram um avanço considerável nos aspectos teóricos da catalogação, uma vez que nos obrigaram a repensar o que fazíamos, por que o fazíamos e, mais importante, para quem o fazíamos. Ao mesmo tempo, os FRBR nos permitiriam trabalhar

\footnotetext{
${ }^{2}$ Apenas à guisa de curiosidade, podem-se empregar: o [código] RDA, a [norma] RDA ou os [recursos] RDA.
} 
com sistemas computacionais entidade-relacionamento, sendo as relações o foco principal dos catálogos. Se não fossem as relações estabelecidas, os catálogos se tornariam meras listas, inventários. Vale lembrar que, originalmente, a palavra grega "catálogo" tinha significado semelhante à palavra latina "classificação".

Os FRBR desenvolveram consideravelmente o primeiro grupo de entidades (obra, expressão, manifestação, item), matéria-prima sobre a qual produzimos nossos registros bibliográficos. Ao segundo grupo de entidades, relativo a responsabilidades (pessoa, entidade coletiva), buscou-se uma complementação por meio dos FRAD (Functional Requirements for Authority Data e acrescentou-se mais uma: família. Por motivos distintos, desde o início o terceiro grupo (conceito, objeto, evento, lugar), relativo aos assuntos, apresentou problemas sobre os quais gostaríamos de observar alguns pontos, embora os FRSAD (Functional Requirements for Subject Authority Data) hajam resolvido a questão.

Quando colocamos em termos simples as entidades do primeiro grupo, podemos verificar que:

a) a entidade obra se distingue por seu nome (título) e respectiva autoria, quando existe. Assim, bastaria a primeira área da ISBD, ou melhor, os pontos de acesso de título uniforme (título original) e autor para identificar uma obra. Como nem sempre o título original mostra-se compreensível a nosso usuário, deveríamos acrescentar-lhe o título convencional, ou o título próprio apresentado na expressão ou na manifestação que se apresenta à catalogação. Portanto, a obra pode identificar-se plenamente e relacionar-se a outras por meio de pontos de acesso;

b) a entidade expressão identifica-se por meio das áreas 1, 2 da ISBD, ou seja, por meio de título, responsabilidades e edição. A área 3 permanece uma incógnita, no sentido de por vezes vincular-se à expressão e, por vezes, à obra, como alertaram Françoise Leresche e Françoise Bourdon (2011). Cabe a nós decidir se as responsabilidades estariam na área 1 , ou em notas, na área 7. Em sistemas automatizados, não há porque colocá-las em notas, quando todos os tipos de responsabilidade podem estar em campos ou subcampos específicos, inclusive recuperáveis, e gerar pontos de acesso próprios. A entidade expressão deveria ser a base do registro bibliográfico, aos quais se acrescentariam campos relativos a: diferentes manifestações e localização do item. Em síntese, a obra permitiria sua plena identificação, inclusive quanto ao assunto, e a expressão permitiria a seleção dentre as várias possibilidades de manifestação. Um registro bibliográfico único vincularia todas as manifestações de uma mesma expressão, de uma mesma obra. Este, a nosso ver, é o princípio básico dos FRBR;

c) a entidade manifestação, secundária sob todos os aspectos, identifica-se pelas áreas 4, 5, 
6 e 8 da ISBD. Em razão do caráter de representação bibliográfica da manifestação, oriundo de práticas bibliotecárias dos últimos 50 ou 60 anos (não de Cutter, que aliou teoria e pragmática), o capítulo 2 do RDA trata diretamente da manifestação, distanciando-se assim dos princípios dos FRBR, apesar das várias assertivas em contrário. Obtemos, por esse meio de centralidade da manifestação, resultados esdrúxulos, como as teses e dissertações brasileiras, simultanea e obrigatoriamente apresentadas em papel (portanto, manuscritas, porque não publicadas) e em formato eletrônico (portanto, publicadas), que geram duas manifestações diferentes e dois registros bibliográficos diferentes! Se considerássemos a obra ou a expressão, e não a manifestação, teríamos um único registro, com duas indicações de manifestação. Pode-se dizer o mesmo de discos em vinil que se tornaram CDs, filmes em rolos que se tornaram DVDs e assim por diante;

d) a entidade item diz respeito somente a cada biblioteca ou centro de documentação em particular. Campos próprios, como número de chamada ou nota, em sistemas automatizados, particularizam os itens, sem problema algum.

As notas, área 7 da ISBD, dividem-se em quatro tipos:

a) as absolutamente inúteis, como: notas de bibliografia e índice, nota sobre dados biográficos do autor (quando não se trata de biografia de extensão respeitável), entre outras;

b) as relativas à identificação da obra ou da expressão, importantes, como certas indicações de títulos ou responsabilidades, que deveriam ter lugar próprio junto às demais e tornar-se recuperáveis;

c) as referentes ao conteúdo propriamente, seja todo/parte (obras em coletâneas, por exemplo, ou faixas de discos), seja de identificação do conteúdo em si (natureza da obra, por exemplo);

d) as que relacionam obras, fundamentais, o espírito mesmo do catálogo; por exemplo, uma sequência de obras baseadas em outras anteriores. Um exemplo muito signficativo é The beggar's opera, obra baseada em canções folclóricas inglesas, escocesas e irlandesas, de Johann Christoph Pepusch e libreto de John Gay (1724). Por sua vez, ela originou a transposição de Kurt Weill, Die Dreigroschenoper, com texto de Bertolt Brecht (1928); que, por seu turno, influenciou a adaptação de Chico Buarque (1978), A ópera do malandro. Tais informações sobre a trajetória de uma obra podem instigar o usuário, levando-o a novas descobertas. Porque precisamos pensar o catálogo como meio, também, de descobrir o que não se conhece.

As relações podem estar aparentes ou escondidas, porque os recursos computacionais de hoje permitem um layout à la carte para o usuário. Existe uma entrada, porém múltiplas 
saídas possíveis - até mesmo da capa do livro, ou disco, ou filme, ou o que for mais adequado ao recurso.

Quanto aos FRAD, essencialmente pragmáticos, geraram alguns capítulos do RDA e o banco de dados de autoridades de nomes do MARC, afastando-se um pouco dos FRBR, na medida em que criaram entidades que talvez fossem mais propriamente atributos. Por outro lado, numa visão centrada no ocidente caucasiano, esqueceu-se de outros autores ou outros tipos de autorias. A dissertação de Aline Franca ${ }^{3}$ aborda a questão interessantíssima e jamais levantada sobre a autoria indígena; no caso, a autoria indígena brasileira. Segundo Franca, a autoria indígena apresenta duas possibilidades: a autoria pessoal ou a autoria do grupo. Ora, como bem esclarece Franca, o grupo indígena não é o que denominaríamos corporate authorship, ou entidade coletiva, ou instituição, ou organização. Em princípio, usou "família", pela ancestralidade comum. Porém, muitas vezes, a "família" indígena se desintegra e forma outros grupos étnicos, com outras culturas, hábitos, crenças e narrativas. Há que se pensar os grupos étnicos de forma bastante ampla, pois encontram-se em todas as partes do mundo. Catalães na Espanha, ciganos em diáspora há séculos, curdos no Oriente Médio, indígenas no Brasil, ou nas Américas (melhor dizendo), grupos africanos de diferentes origens e Histórias. Portanto, há muito a questionar nos FRAD, que merecem um trabalho à parte, inclusive para escolha do termo antropológico correto que definiria a responsabilidade étnica.

Os FRSAD, o modelo mais conceitual da família FRBR, apresentam de forma irretocável as diferentes visões de um assunto, as entidades e os atributos. Abandonam os assuntos apresentados nos FRBR, com toda razão. Existia uma lacuna naquele terceiro grupo de entidades, que ignorava a Energia ranganathiana ou os processos em outros sistemas temáticos. Por outro lado, tornar-se-ia impossível conciliar os diferentes métodos e instrumentos usados, em todo o mundo, para identificar os assuntos de uma obra. Ademais, por mais apurado que seja o controle das linguagens documentárias, há que considerar o fator humano na indexação. Os indexadores carregam em si diferentes formações, culturas, crenças, idiomas, assim como públicos diversos a serem alcançados. Clarinda Lucas (2000) fez uma bem fundamentada análise de mesma obra indexada por diferentes bibliotecas, encontrando diferentes enfoques. Portanto, apesar das ótimas intenções do RDA em lidar com assuntos um avanço considerável para os catalogadores - nem sempre a questão é tranquila e pragmática.

A família FRBR já foi objeto de muitas análises e de dois diferentes fascículos do periódico Cataloging \& Classification Quarterly, em diferentes períodos, inclusive por alguns

\footnotetext{
${ }^{3}$ Em andamento e já aprovada no exame de qualificação (2014) no Mestrado Profissional em Biblioteconomia da UNIRIO.
} 
respeitados autores europeus.

A melhor análise sobre o RDA nos veio da França, que criou um grupo de estudos com este fim, cujos resultados Françoise Leresche e Françoise Bourdon resumiram, e dos quais retiramos alguns pontos-chave, com os quais concordamos: "O RDA permanece de fato muito fiel ao AACR" (2011, p. 2); "As normas ISO são quase totalmente ignoradas [...] e pode-se notar, também, uma falta de referência aos documentos da IFLA, tais como Nomes de pessoas [...]" (ibidem) - problema que sentimos particularmente para os nomes de língua portuguesa. "Pode-se também afirmar que o RDA propõe UMA interpretação específica do modelo FRBR" (ibidem). Por fim, uma importante conclusão: "O relatório do Comitê de Coordenação da Testagem do RDA nos Estados Unidos confirma a existência de um certo consenso sobre questões levantadas pelo RDA hoje: falta de internacionalização, tratamento precário de recursos audiovisuais e de materiais especiais etc." (ib., p.6).

Em nossa opinião, a lacuna principal é a questão da internacionalização, que se apresenta, por exemplo, na retirada de abreviaturas latinas consagradas, causando ambiguidade nos registros, pelo menos para nós, de língua latina.

O grupo de estudos europeu do RDA, EURIG, vem elaborando uma série de propostas para inclusão ou mudanças nas regras, analisadas pelas instituições responsáveis pelo RDA, embora os estudos caminhem muito lentamente. Por sua vez, em 2009, publicou-se um novo código italiano de catalogação (REGOLE, 2009), bem mais completo sob certos aspectos, inclusive os teóricos.

Cabe a nós a pergunta: será o RDA, de fato, o novo código internacional tão esperado? Caso o seja, precisamos pensar nos problemas serí́ssimos de tradução e custos. Quando da tradução do AACR2, não houve permissão para inclusão, no texto, de decisões brasileiras, tanto no que se refere à descrição, quanto no tocante aos cabeçalhos de nomes de pessoas, lugares e entidades coletivas, sempre colocados em apêndice, nota de rodapé ou documentos externos. Devido aos custos, toda a tradução baseou-se em trabalho voluntário ${ }^{4}$. O RDA tem um custo maior ainda, inclusive de direitos autorais. Como resolver este problema internacionalmente? De um ponto de vista muito particular de nosso grupo de estudos (ressaltamos não representarmos nenhuma unanimidade brasileira), acreditamos que apenas uma adaptação poderia conformar nossas necessidades e nossa multiculturalidade a um novo código de catalogação. Em que pese seu inquestionável valor, a nosso ver ainda não se pode aceitar como resolvido e acabado este novo código anglo-americano. O RDA permanece uma questão em aberto, embora traga melhorias à prática da catalogação.

\footnotetext{
${ }^{4}$ Observe-se que a maioria dos participantes faleceu nesses últimos anos.
} 
Por outro lado, Françoise Leresche e Françoise Bourdon também constataram que "Atualmente, o RDA apresenta a versão mais completa desta abordagem [aos FRBR] e é isto o que o torna valioso" $(2010$, p. 5). Certamente, há que se respeitar o infatigável e monumental trabalho realizado pela equipe anglo-saxônica para a produção do RDA. Há que se respeitar a busca de alinhamento à família FRBR. Há que se respeitar certos avanços efetivos apresentados pelo RDA, como o fim da entrada principal e da regra dos três, e a maior abrangência para documentos eletrônicos. Há que se respeitar, por fim, este grupo de estudiosos catalogadores que criaram o RDA. Devido a este gigantesco esforço, ainda devemos discuti-lo. A copiar Barbara Tillett, dizemos que este é um tempo maravilhoso para ser um catalogador.

\section{Referências}

FRANCA, Aline da Silva.A representação bibliográfica da autoria indígena brasileira. Orientação de Naira Silveira. 2014. 57 f. Projeto de pesquisa apresentado à banca de qualificação (Mestrado Profissional em Biblioteconomia)--Programa de Pós-Graduação em Biblioteconomia, Universidade Federal do Estado do Rio de Janeiro, 2014. INTERNATIONAL FEDERATION OF LIBRARY ASSOCIATIONS AND INSTITUTIONS. IFLA Study Group on the Functional Requirements for Bibliographic Records. Functional Requirements for Bibliographic Records: Final Report. 2009. Disponível em: <http://www.ifla.org/files/assets/cataloguing/frbr/frbr 2008.pdf>. Acesso em: 10 jan. 2013. IME-ICC: IFLA Meetings of Experts on an International Cataloguing Code. 2012. Disponível em <http://www.ifla.org/node/576>. Acesso em: 11 set. 2013.

. Statement of International Cataloguing Principles. 2009. Disponível em $<$ http://www.ifla.org/publications/statement-of-international-cataloguing-principles $>$. Acesso em: 17 out. 2013.

JOINT STEERING COMMITTEE FOR REVISION OF AACR. Resource description \& access: RDA. American Library Association, 2005.

JOINT STEERING COMMITTEE FOR DEVELOPMENT OF RDA. Historic documents: Outcomes of the Meeting of the Joint Steering Committee Held in Chicago, U.S.A, 24-28 April 2005. 2009. Disponível em: <http://www.rda-jsc.org/0504out.html>. Acesso em: 17 out. 2013.

. RDA: Resource Description and Access. 2013. Disponível em: <http://www.rdajsc.org/rda.html>. Acesso em: 11 dez. 2013. 
LERESCHE, Françoise; BOURDON, Françoise. RDA in Europe: Report of the work in progress in France: Proposal for an EURIG Technical Meeting in Paris. In: RDA: Resource Description and Access: Foundations, Changes and Implementation - Satellite meeting on RDA at the 77th IFLA General Conference and Assembly. San Juan, Puerto Rico, 12 Aug. 2011. Disponível em: $<$ http://rda-en-france.enssib.fr/sites/rda-en-france.enssib.fr/files/RDA in Europe Report of the work in progress in France 2011-08.doc>. Acesso em: 17 set. 2013.

LUCAS, Clarinda R. Leitura e interpretação em Biblioteconomia. Campinas, SP: Ed. UNICAMP, 2000 .

MEY, Eliane Serrão Alves. Catalogação e descrição bibliográfica: contribuições a uma teoria. Brasilia: ABDF, 1987.

. Introdução à catalogação. Brasilia, D.F.: Briquet de Lemos/Livros, c1995.

MEY, Eliane Serrão Alves; SILVEIRA, Naira Christofoletti. Catalogação no plural. Brasília, DF: Briquet de Lemos, 2009.

REGOLE italiane di catalogazione: REICAT. [Roma: ICCU], jan. 2009. 380p. Disponível em: <http://www.iccu.sbn.it/upload/documenti/REICA bozza complessiva genn2009.pdf>

RODRÍGUEZ GARCÍA, Ariel Alejandro. Elementos para reflexionar sobre el nuevo estándar para la descripción y acceso a recursos. Biblioteca Universitaria: Revista de la Dirección General de Bibliotecas de la UNAM, v.13, n.1, p.55-63, enero-junio 2010. Disponível em: <http://revistas.unam.mx/index.php/rbu/article/view/23925. Acesso em: 11 set. 2013.

TILLETT, Barbara. Bibliographic relationships in library catalogues. International Cataloguing and Bibliographic Control, v.17, n.1, p.3-6, Jan./March 1988.

. RDA (Resource Description and Access): Status Report on the New Cataloguing Code = Informe sobre el nuevo código de catalogación. In: Encuentro Nacional de Catalogación y Metadatos, 2., México, D.F., 24-26 oct. 2007. En los umbrales de un nuevo código de catalogación: memoria del Segundo Encuentro de Catalogación y Metadatos. México, D.F.: UNAM, Centro Universitario de Investigaciones Bibliotecológicas, 2008.

. The FRBR Model. ALCTS Institute on Metadata and AACR2, San Jose, CA., April 4-5, 2003. Disponível em: http://www.loc.gov/catdir/cpso/frbreng.pdf. Acesso em: 11 out. 2013. 